\title{
Necessidades de saúde da pessoa com deficiência: a perspectiva dos sujeitos por meio de histórias de vida*
}

Marilia Bense Othero ${ }^{1}$

José Ricardo de Carvalho Mesquita Ayres²

OTHERO, M.B.; AYRES, J.R.C.M. Healthcare needs of people with disabilities: subjects' perspectives through their life histories. Interface - Comunic., Saude, Educ., v.16, n.40, p.219-33, jan./mar. 2012.

This study aimed to identify the healthcare needs of people with disabilities, from the subjects' perspective. We conducted a qualitative study, through the life history technique. The study included people with congenital or acquired physical, hearing and visual disabilities who were attended through the Brazilian national health system (SUS). Their experience of disability; independence, autonomy and support; access and rights; the meaning of the interventions; and actions and strategies were discussed. In relation to healthcare needs, eleven strands were listed: access; psychosocial support; general health issues; autonomy and independence; dispensing of assistive technology equipment and devices; information/guidance; prevention/early diagnosis; recognition and guaranteeing of rights; (re)encountering of meaningful activities; validation and help in building subjects' own coping strategies; and bonding with healthcare professional. It was found that the needs identified by the subjects included specific aspects of healthcare, but also encompassed other dimensions, thus indicating the importance of comprehensive intersectoral actions.

Keywords: Disabled persons. Health needs. Life history. Qualitative research.
Este trabalho teve como objetivo identificar as necessidades de saúde das pessoas com deficiência, pela ótica dos sujeitos. Realizouse um estudo qualitativo, por meio da técnica da história de vida; foram incluídas pessoas com deficiência física, auditiva e visual, congênita e adquirida, e com atendimento no SUS. Discutiu-se: a vivência da deficiência; independência, autonomia e apoio; acesso e direitos; sentidos das intervenções; ações e estratégias. Em relação às necessidades de saúde, foram elencados onze eixos: Acesso; Apoio psicossocial; Aspectos gerais de saúde; Autonomia e independência; Dispensação de equipamentos e dispositivos de tecnologia assistiva; Informação/orientação; Prevenção/diagnóstico precoces; Reconhecimento e garantia de direitos; (Re)Encontro com atividades significativas; Validação e ajuda na construção de estratégias próprias de enfrentamento; Vínculo com profissional de saúde. Verificase que as necessidades identificadas pelos sujeitos incluem aspectos específicos da assistência em saúde, mas englobam outras dimensões, indicando a importância de ações integrais e intersetoriais.

Palavras-chave: Pessoas com deficiência. Necessidades de saúde. História de vida. Pesquisa qualitativa.
* Elaborado com base em Othero (2010); pesquisa aprovada pelo Comitê de Ética da Faculdade de Medicina da USP.

1,2 Departamento de Medicina Preventiva, Faculdade de Medicina, Universidade de São Paulo. Medicina Preventiva / Secretaria de Pós-Graduação Av. Dr. Arnaldo, 455 $2^{\circ}$ andar - sala 2162. Cep.01246-903. Email: marilia.othero@usp.br 


\section{Introdução}

A temática das pessoas com deficiência é de relevância para o campo da Saúde Coletiva, e - nas últimas décadas - vêm ocorrendo avanços no que diz respeito a dados existentes, aspectos teóricoconceituais, políticas e práticas em saúde.

Segundo a Organização Mundial de Saúde, 10\% da população mundial apresentam algum tipo de deficiência (Almeida, Tessi, Oliver, 2000). No Brasil, segundo o Censo Demográfico de 2000, o número de pessoas com deficiência é de 24,5 milhões de pessoas, correspondendo a, aproximadamente, $14,5 \%$ da população, sendo incluídas pessoas com: deficiência visual $(48,1 \%)$, motora $(22,9 \%)$, auditiva (16,7\%), mental (8,3\%) e física (4,1\%) (IBGE, 2003).

A nova classificação das deficiências, proposta pela OMS em 2001 - "Classificação Internacional de Funcionalidade, Incapacidade e Saúde (CIF)" - é avaliada como um avanço na compreensão da deficiência, pois engloba o sujeito de maneira mais integral, e extrapola o referencial biomédico, na medida em que - a partir de seus quatro eixos: função corporal, estrutura corporal, atividades e participação, fatores ambientais - descreve a funcionalidade e a incapacidade com base naquilo que o sujeito consegue e não consegue realizar em sua vida diária (Farias, Buchalla, 2005). A Convenção Internacional sobre os Direitos das Pessoas com Deficiência (ONU, 2006) também representou avanços, promulgando e reforçando direitos de cidadania das pessoas com deficiência, incluindo aspectos relacionados à saúde.

No Brasil, ainda que distante das práticas concretas, o Sistema Único de Saúde trouxe modificações positivas, propondo a assistência às pessoas com deficiência segundo o modelo assistencial geral, e a partir dos mesmos serviços utilizados por quaisquer cidadãos (Rocha, 2006; Almeida, Tessi, Oliver, 2000; Ghirardi, 1999). Vale mencionar ainda a "Política Nacional de Saúde da Pessoa com Deficiência", que norteia o campo da saúde da pessoa com deficiência no SUS (Brasil, 2002).

Porém, ainda que estes aspectos positivos no campo da assistência em saúde sejam descritos nas últimas décadas, a assistência às pessoas com deficiência no Brasil continua associada à esfera filantrópica, com o modelo médico prevalecendo, com foco nos aspectos orgânicos e individuais da deficiência (Bernardes et al., 2009; Rocha, 2006; Almeida, Tissi, Oliver, 2000).

Em relação às práticas concretas em saúde, é preciso considerar também que, muitas vezes, estas não incluem os valores, saberes e necessidades daqueles que são atendidos. Segundo Pereira (2008), é preciso considerar que os discursos e práticas produzidos em torno da deficiência são externos a ela, funcionando como um amontoado de dados, em que informações procedentes e válidas misturam-se a dados distorcidos por estereótipos e preconceitos.

Diante deste panorama, foi proposto o estudo aqui apresentado, que tem como objetivo identificar as necessidades de saúde da pessoa com deficiência, pela ótica destes sujeitos. Como principal referencial teórico norteador, adotou-se a perspectiva da integralidade e do cuidado em saúde.

\section{Necessidade de saúde, cuidado e integralidade}

Segundo Schraiber e Mendes-Gonçalves (2000), as necessidades de saúde são um aspecto importante para produzir reflexões sobre os serviços e as referências que os embasam. MendesGonçalves (1992) afirma que as necessidades aparecem como aquilo que precisa ser satisfeito para que um ser continue sendo um ser, sabendo-se que, para toda necessidade, há um processo de trabalho correspondente, cujo produto potencialmente a satisfaz, reiterando-se ou ampliando-se esta necessidade, e dando origem a outro processo de trabalho. Ressalta-se que os indivíduos são sócio-historicamente determinados e que, portanto, as necessidades também são históricas e sociais, determinadas pela existência concreta dos mesmos (Campos, Mishima, 2005).

A procura ativa por intervenção e cuidados de saúde em um serviço é caracterizada como demanda, que também representa o consumo destes serviços; esta busca tem origem em um carecimento, ou seja, algo que o indivíduo entende que deve ser melhorado ou corrigido. O resultado das intervenções sobre este carecimento é reconhecido como uma necessidade de saúde, sendo a própria intervenção também reconhecida como tal (Schraiber, Mendes-Gonçalves, 2000). 
A partir de Cecílio (2006): a demanda é o pedido explícito do usuário, modelada pela oferta feita pelos serviços. As necessidades de saúde são as traduções realizadas pela equipe conjuntamente com este usuário, no processo de intervenção em saúde e - novamente - social e historicamente determinadas. $\mathrm{O}$ autor apresenta uma taxonomia das necessidades de saúde, em quatro grandes conjuntos: ainda que maneiras diferentes de viver levem a diferentes necessidades de saúde, "ter boas condições de vida" é um primeiro conjunto de necessidades. Acesso ao consumo de tecnologias capazes de melhorar e/ou prolongar a vida é outra dimensão, ressaltando que as tecnologias são várias (leve, leve-dura, dura), e não deve haver hierarquização entre elas. A criação de vínculos "(a) efetivos" entre usuários e profissionais é considerada outra categoria das necessidades de saúde, no entendimento de que a relação entre usuários e profissionais/serviços não deve se restringir à adscrição da clientela, mas ser, sim, um verdadeiro encontro de subjetividades. Ter graus crescentes de autonomia nos "modos de andar a vida" é a última categoria trazida pelo autor. Formulada originalmente por Georges Canguilhem (1982), os modos de andar a vida são entendidos aqui como a reconstrução dos sentidos da vida após o processo de adoecimento e da possibilidade de fazer escolhas acerca de sua vida, pelos próprios sujeitos. Merhy (2000) acrescenta a necessidade de ser alguém singular com direito à diferença, isto é, ser sujeito de direitos e cidadão, mas ser nominal, ser respeitado em suas necessidades especiais, ser incluído.

Obviamente, as respostas a esta gama de necessidades, e seus múltiplos fatores envolvidos, não se restringem à atuação de um único profissional, ou mesmo somente da área da saúde. As ações devem ser multiprofissionais, interdisciplinares e intersetoriais, para que sejam possíveis respostas mais efetivas às necessidades de saúde das pessoas. Cecílio (2006) afirma que deve haver uma articulação entre as diversas áreas, por meio de ações integrais.

A integralidade é principio norteador para a apreensão das necessidades dos sujeitos atendidos, bem como para a compreensão e formulação das respostas a serem dadas (Ayres, 2009), incluindo aspectos muito importantes: as necessidades não se resumem à doença; a prevenção e a assistência devem estar articuladas, os problemas são complexos e envolvem o contexto sociocultural, o usuário é um sujeito (com história, valores, desejos).

Como já mencionado em relação à saúde da pessoa com deficiência no Brasil, é indiscutível que o SUS possibilitou mudanças, porém, a reabilitação praticada nas instituições existentes mostra que a racionalidade médica institui a melhora ou o aumento do desempenho funcional como missão exclusiva, pouco abordando os processos que envolvem a vida com deficiência. Articuladamente a isso, este modelo traz a propagação da ideia de que a integração social dependeria - fundamentalmente de conquistas individuais (Rocha, 2006; Almeida, Tissi, Oliver, 2000).

São diversos os serviços e proposições existentes no campo da atenção à saúde da pessoa com deficiência, mas, conforme Ayres (2004) ressalta, as práticas em saúde - apesar de um grande desenvolvimento técnico-científico - encontram limitações para responder efetivamente às complexas necessidades de saúde das pessoas, sendo necessários novos referenciais para a assistência, pautados nos conceitos como integralidade e cuidado.

O cuidado é apontado por Lacerda e Valla (2006) como uma dimensão da integralidade, incluindo o acolhimento, os vínculos de intersubjetividade e a escuta dos sujeitos. O cuidado deve ser entendido como "designação de uma atenção à saúde imediatamente interessada no sentido existencial da experiência de adoecimento, físico ou mental, e, por conseguinte, também das práticas de promoção, proteção ou recuperação da saúde" (Ayres, 2004, p.22).

Segundo Lacerda e Valla (2006), o modelo médico é pautado no diagnóstico e tratamento de doenças definidas pelo saber científico, priorizando-se as alterações e lesões do corpo, em detrimento do sujeito e suas necessidades. Há pouco espaço para a escuta dos sujeitos e seus sofrimentos, para o acolhimento e para a atenção e cuidado integral à saúde. De acordo com Almeida, Tissi e Oliver (2000), na prática da assistência à saúde das pessoas com deficiência, é possível identificar que, muitas vezes, as principais demandas e necessidades não estão na gravidade orgânica ou nos comprometimentos funcionais, mas, sim, em outros processos, sociais e relacionais, que condicionam desigualdades entre os cidadãos, havendo a necessidade de responder a isso do ponto de vista da organização dos serviços e práticas. 
Diante disso, Ayres (2004) propõe a ampliação do horizonte normativo para a dimensão existencial do adoecimento (e, portanto, da condição do existir com deficiência), relacionada diretamente com o conceito de cuidado, trazido anteriormente. Propõe, então, um diálogo entre a normatividade morfofuncional (que tem seu papel fundamental, sem dúvida) e normatividades de outras ordens, implicando a abertura de autêntico interesse em ouvir o outro, e todas as demandas que ele possa trazer. Conforme posto por Merhy (2000), há a necessidade de ser singular, e "Isso implica a busca de construir, a partir do diálogo com o outro, projetos terapêuticos individualizados" (Mattos, 2004, p.1415).

Enfim, este estudo propõe - no âmbito da saúde das pessoas com deficiência - trazer, para o primeiro plano das discussões teóricas e práticas, as demandas e necessidades de saúde identificadas pelos próprios sujeitos, em seus contextos de vida, possibilitando diálogo e reflexão com os referenciais que subsidiam as ações neste campo.

\section{Metodologia}

A partir do objetivo estabelecido, adotou-se a metodologia qualitativa, escolhendo-se, como técnica de produção de dados, a história de vida. Segundo Rocha e Brunello (2007), esta técnica se caracteriza por colher informações sobre a vida pessoal dos indivíduos, sendo relatadas: suas percepções pessoais, os aspectos que marcaram sua experiência, os acontecimentos vividos em suas trajetórias. Segundo Gonçalves e Lisboa (2007), há um entrelaçamento pessoal e social na narração das histórias de vida, em um relato de um sujeito imerso em uma cartografia cultural e social que, com sua singularidade, rearranja e se reapropria do social. Portanto, na pesquisa aqui apresentada, a opção pela história de vida deu-se pelo método de possibilitar oportunidades de escuta singular das pessoas com deficiência e sua ótica de necessidades, a partir do objetivo estabelecido já anteriormente descrito.

A pesquisa foi realizada no período entre março de 2008 e agosto de 2010.

Foram realizadas entrevistas em profundidade, com pessoas com deficiência física, auditiva e visual, manifestadas na primeira infância e na idade adulta para cada categoria, totalizando seis sujeitos. Foram incluídas pessoas com idade entre quarenta e 65 anos, do sexo feminino ou masculino, todas com histórico de atendimento em serviços de atenção à pessoa com deficiência no SUS. A divisão por tipos de deficiência foi definida para possibilitar a identificação de especificidades de cada um delas, e os temas comuns a todas. O critério de idade (40-65 anos) foi escolhido para facilitar que o informante tivesse uma maior experiência de vida, conseguindo-se potencialmente abordar uma maior gama de aspectos da vida com deficiência; considerou-se até 65 anos para que não ficassem muito demarcados aspectos voltados ao envelhecimento. O critério de atendimento no SUS buscou homogeneizar nível de uso de serviços. E, por último, optou-se por um recorte de pessoas com deficiências manifestadas na primeira infância e manifestadas na idade adulta, justificado pelo fato de que são "modos de andar a vida" muito diferentes para um sujeito que viveu desde muito jovem com a deficiência e aquele que lidou com uma grande ruptura em sua vida.

Foram considerados critérios de exclusão: portadores de deficiências múltiplas (mais de um tipo de deficiência associado) e pessoas com deficiência intelectual, pois, para que as mesmas pudessem contar sua história de vida, outros métodos seriam mais adequados, e não a entrevista somente.

A partir destes critérios, buscou-se a diversificação, possibilitando abarcar o campo de investigação por meio de sujeitos diferentes, conhecedores e pertencentes a ele (Gonçalves, Lisboa, 2007). Os sujeitos da pesquisa foram captados pelo mecanismo de indicação interpessoal (Schraiber, 1995), por meio da rede de contatos da pesquisadora. Para a finalização do processo foi utilizado o critério da saturação.

As entrevistas foram feitas em três tomadas, com duração aproximada de uma hora para cada, em local escolhido pelo entrevistado; o intervalo entre as entrevistas variou de um a 15 dias. Os encontros foram gravados (permitindo o registro total do relato), sendo utilizado roteiro de questões amplo, a fim de estimular a livre narração. Para cada entrevistado, foi entregue o Termo de Consentimento Livre e 
Esclarecido, sendo lido conjuntamente, assegurando-se o compromisso de sigilo de sua identidade. No Quadro 1, constam as informações principais sobre os sujeitos entrevistados, que foram identificados por nomes fictícios, garantindo a confidencialidade da pesquisa.

Quadro 1. Sujeitos participantes da pesquisa

\begin{tabular}{|l|l|l|l|l|l|l|}
\hline Nome & Idade & Profissão & Moradia & Tipo de deficiência & Local da entrevista & $\begin{array}{l}\text { Datas da } \\
\text { entrevista }\end{array}$ \\
\hline Sr. Jair & 62 & Aposentado & São Paulo & $\begin{array}{l}\text { Visual manifestada na } \\
\text { idade adulta }\end{array}$ & $\begin{array}{l}\text { Residência do } \\
\text { entrevistado }\end{array}$ & $\begin{array}{l}06 / 10 / 2008 \\
13 / 10 / 2008 \\
20 / 10 / 2008\end{array}$ \\
\hline Ricardo & 42 & $\begin{array}{l}\text { Operador de } \\
\text { telemarketing }\end{array}$ & São Paulo & $\begin{array}{l}\text { Física manifestada } \\
\text { na primeira infância }\end{array}$ & $\begin{array}{l}\text { Local de trabalho } \\
\text { ensidência do } \\
\text { entrevistado }\end{array}$ & $\begin{array}{l}27 / 03 / 2009 \\
28 / 03 / 2009 \\
31 / 03 / 2009\end{array}$ \\
\hline Cristina & 45 & $\begin{array}{l}\text { Técnica de } \\
\text { enfermagem }\end{array}$ & São Paulo & $\begin{array}{l}\text { Auditiva manifestada na } \\
\text { idade adulta }\end{array}$ & $\begin{array}{l}\text { Local de trabalho do } \\
\text { entrevistado }\end{array}$ & $\begin{array}{l}01 / 06 / 2009 \\
08 / 06 / 2009 \\
22 / 06 / 2009\end{array}$ \\
\hline Ângela & 47 & Do lar & São Paulo & $\begin{array}{l}\text { Física adquirida } \\
\text { manifestada na idade } \\
\text { adulta }\end{array}$ & $\begin{array}{l}\text { Centro de } \\
\text { reabilitação }\end{array}$ & $\begin{array}{l}19 / 06 / 2009 \\
03 / 07 / 2009 \\
17 / 07 / 2009\end{array}$ \\
\hline Fátima & 55 & Estudante & Santos & $\begin{array}{l}\text { Visual manifestada na } \\
\text { primeira infância }\end{array}$ & $\begin{array}{l}\text { Instituição } \\
\text { filantrópica }\end{array}$ & $\begin{array}{l}22 / 03 / 2010 \\
29 / 03 / 2010 \\
05 / 04 / 2010\end{array}$ \\
\hline Rubens & 54 & Pedreiro & São Paulo & $\begin{array}{l}\text { Auditiva manifestada na } \\
\text { primeira infância }\end{array}$ & $\begin{array}{l}\text { Centro de saúde e } \\
\text { residência da irmã }\end{array}$ & $\begin{array}{l}14 / 05 / 2010 \\
21 / 05 / 2010 \\
28 / 05 / 2010\end{array}$ \\
\hline
\end{tabular}

Além das entrevistas, também foi realizado diário de campo, no qual constaram: anotações detalhadas e sistematizadas sobre a entrevista, impressões, comportamentos descritos, espaço físico, comentários, reflexões etc. Schraiber (2005) ressalta que, com o diário de campo, abre-se a possibilidade de registrar informações obtidas fora do momento da entrevista propriamente dita.

O passo seguinte foi a transcrição completa das narrativas, e, depois, a edição do texto, retirandose: erros gramaticais, digressões, as falas do entrevistador, pausas e titubeações, cortes de frases ou ideias, interrupções; obteve-se um material final de cento e vinte páginas com as histórias. Cada uma delas foi enviada ao respectivo sujeito por correio, junto com uma carta de apresentação, havendo abertura para a sugestão de modificações por parte dos mesmos, a fim de garantir sua fidedignidade ao sujeito da pesquisa. Nenhuma modificação foi sugerida.

A análise foi feita em três níveis, buscando-se as palavras-chave, os temas emergentes e as tendências gerais, conforme proposto por Houltz (1997). Foram realizadas muitas leituras do material e, a cada uma delas, foram escritos comentários e identificados os trechos significativos. Com base na análise, foi redigido um texto descritivo, produzindo-se um diálogo entre os núcleos temáticos identificados e os referenciais da Saúde Coletiva adotados. Também foi elaborado um quadro sintético, buscando-se as tendências gerais a partir do material, em confluência com o objeto central da pesquisa: necessidades de saúde da pessoa com deficiência.

\section{A partir das narrativas... a discussão e análise}

Foi possível elencar diversos aspectos da vida da pessoa com deficiência e sua relação com o contexto da assistência em saúde. Das narrativas, emergem cinco grandes temas ligados às necessidades da pessoa com deficiência, construídos com base nos referenciais teóricos adotados 
(integralidade e cuidado): a vivência da deficiência; independência, autonomia e apoio; acesso e direitos; sentidos das intervenções; ações e estratégias.

Foram diversas as falas que emergiram nas narrativas e suscitaram as reflexões para cada um destes temas. Optou-se por apresentar aqui apenas pequenos trechos ilustrativos.

Vivência da deficiência. Os principais assuntos discutidos foram: as especificidades do viver com deficiência, os contatos com o mundo, as relações com as pessoas (em que a tônica da superproteção ou da discriminação e do preconceito estiveram fortemente presentes), o ritmo e a organização do cotidiano. Considerou-se importante discutir a vida com deficiência, uma vez que pouco dela acaba aparecendo nas proposições práticas em saúde.

Ainda que já proposto pelo recorte metodológico, ressalta-se que as diferenças entre o caráter precoce ou tardio da deficiência e suas implicações para a vivência cotidiana foram fortemente marcadas: a ruptura versus o apreender o mundo por diferentes modalidades sensório-motoras. É preciso considerar também que outras características farão parte deste processo: história de vida, organização familiar, rede social, aspectos culturais, aspectos financeiros, valores, entre outros.

"Eu acho que é difícil você nascer surdo e não ouvir, mas quem ouve e depois vai perdendo... Esse contato é ruim...". [Cristina]

“[...] Porque eu já vim de criança, então minhas oportunidades foram diferentes do que aquele cara que já tinha uma, uma vida de motoboy ou sei lá, mas caiu e se acidentou, ou tinha o seu carro, bateu e não seu quê, e ficou paraplégico... Mas aí já tinha suporte, tinha uma vida, um trabalho...". [Ricardo]

O desejo (e uma possível busca) pela "normalidade", modelo adotado como referência, fica marcado como um mecanismo de enfrentamento da condição de irreversibilidade imposta pela deficiência. Os sentimentos mobilizados são diversos, a partir da história singular, do contexto em que se insere, e do tipo de deficiência; porém, palavras como trauma, vergonha, medo, decepção permeiam o discurso. Acostumar-se, adaptar-se, suportar, não perder a esperança, aprender a conviver são alguns dos nomes dados pelos entrevistados aos mecanismos de enfrentamento, que se relacionam intrinsecamente à história e aos recursos internos e externos de cada um.

"As pessoas com deficiência que eu conheço ainda tem muito trauma. A deficiência traz um trauma pra pessoa. Eu sinto isso sim, mas traz mesmo pô. Só a ansiedade de eu querer, de eu estar conversando com uma pessoa e de querer enxergar, aquilo já é um trauma que sempre a pessoa vai carregar. Aquela ansiedade de ver a pessoa, entende... Porque é sempre um trauma, é a mesmo coisa quem tem acidente na mão, e ao pegar em algum objeto não pega, tem sacrifício pra pegar nas coisas, porque a mão falta dois, três dedo. Tem diferença... Até pra escrever, às vezes vai aprender a escrever com a esquerda. Tudo isso a pessoa tem trauma, dificuldade...". [Sr. Jair]

A vivência da deficiência extrapola as experiências pessoais e familiares, de âmbito privado: os amigos, os espaços públicos, o contato com outras pessoas na comunidade pertencem a este panorama. O principal tema que desponta neste aspecto é o preconceito.

“[...] Agora na rua, de vez em quando você encontra preconceito. De vez em quando... O pessoal ainda não se acostumou... A sociedade ainda não se acostumou com os deficientes visuais... [...] Eu acho que ainda a sociedade precisa aprender a trabalhar mais e mais com o deficiente. De tipo qualquer, tanto o visual quanto o paraplégico. E a gente ainda tem muita dificuldade na rua". [Fátima]

Em relação às explicações sobre a deficiência, a religião (e a ideia de castigo, culpa, transcendência ou aprendizado), a noção de acidente e/ou fatalidade, e a genética/hereditariedade são concomitantes 
em vários relatos. Cada um, com sua história, crenças, concepções e vivências concretas, vai encontrando e construindo significados para a sua própria vivência de ter uma deficiência, tendo, na aprendizagem e na transformação, focos importantes de sentido. E estas experiências vão sendo ressignificadas ao longo do percurso da vida (e, até mesmo, no próprio processo de produção do discurso, na entrevista).

Estes sentidos, significados, valores e concepções banham a relação entre as pessoas no mundo. A deficiência - em seus diversos aspectos - é uma questão do encontro com a diferença, do relacionarse com o que é diferente, com o "outro". A alteridade faz a mediação da pessoa com deficiência consigo própria e com o mundo, e deverá ser considerada na assistência propriamente dita também, uma vez que tratamos aqui das necessidades de saúde.

Independência, autonomia e apoio. Neste tema, autonomia e independência aparecem como questões centrais no discurso dos sujeitos entrevistados, identificadas como algo que propicia senso de dignidade e liberdade. O que Cecilio (2006) aponta como um dos conjuntos de necessidades de saúde, a "autonomia nos modos de andar a vida", é contemplada no limite no caso das pessoas com deficiência. A partir das histórias, fica explícita, por parte dos sujeitos, a valorização de mecanismos que permitam a pessoa com deficiência a aprender, a experimentar e a - concretamente - realizar tarefas e atividades de maneira independente, seja por parte da família quanto das instituições.

"[...] E tem uma coisa de bom, a minha mãe, ela nunca me criou como deficiente visual... Ela sempre foi uma pessoa que me ensinou a fazer tudo... Tudo! [...] E graças a Deus, a minha mãe ela nunca me criou como deficiente visual... Graças a Deus! Eu louvo a Deus por isso, porque também se tivesse me criado, tinha me paparicado muito e eu tinha sofrido mais... [...] São essas coisas que a família precisa deixar fazer, a família precisa incentivar, e o Lar aqui também precisa incentivar, porque vai ser muito pior lá fora ou com outra pessoa. [...] Primeiro já começando pela família: tem que incentivar a fazer, dando prejuízo ou não, e quando estiver na escola, a escola não tem que paparicar, porque se paparicar...". [Fátima]

Porém, alinhada à ideia de autonomia/independência, está a noção de apoio e ajuda, como fundamental para as pessoas com deficiência, com base em uma atitude de respeito, compreensão e acolhimento às diferenças. Diniz (2007) ressalta que a sobrevalorização da independência é um ideal perverso para muitas pessoas com deficiência, pois há aqueles que têm incapacidades mais graves e que jamais terão habilidades para a independência ou capacidade para o trabalho, não importando quanto as barreiras sejam eliminadas. Os entrevistados trouxeram que o mais importante é a maneira de prestar apoio e estar junto da pessoa com deficiência, estabelecendo-se uma relação de respeito, compreensão e cooperação. E as fontes de apoio e ajuda podem ser: a família, os amigos, os profissionais de saúde, as instituições, os prestadores de serviços, entre outros.

“... E o acompanhamento que eu digo não é a pessoa vir com você, mas em casa, não se afastar ou ficar com dó de você, não deixar você fazer nada. Isso acaba com a gente! Claro, tem que ter cuidado com a gente, mas não precisa ser aquele cuidado que chega a ser pegajoso, irritar...". [Ângela]

É importante ressaltar que, segundo Pereira (2008), a ocorrência de uma deficiência altera em maior ou menor grau - os modos de vida da pessoa e da família, considerando-se também o universo sociocultural no qual estes estão imersos, uma vez que nele (e a partir dele) estão colocadas as concepções, as explicações e os comportamentos próprios daquele contexto. E pode haver preocupações em torno do representar uma sobrecarga aos familiares: o medo de uma possível dependência, ou de uma piora nesta condição, é um fardo e uma preocupação constante, temas também trazidos pelas narrativas.

Acesso e direitos. Neste tópico, emerge a importância de se ampliarem as possibilidades da pessoa com deficiência ser/estar no mundo como sujeito de direitos e como cidadã, em seu sentido mais ampliado: acessibilidade urbana e arquitetônica, oportunidades, lazer, cultura, trabalho, 
educação, saúde, dispensação de equipamentos de auxílio, transporte, informação etc. Ainda que garantido por lei, o acesso a muitos direitos conquistados pelas pessoas com deficiência permanece falho, com muitos relatos de dificuldades e movimentos em busca de conquista.

A informação também desponta como um tema importante: acesso aos serviços, direitos das pessoas com deficiência, trâmites burocráticos na dispensação de medicamentos e dispositivos de auxílio, entre outros.

"E direito a informação. Acho que cidadão, não só a pessoa com deficiência, mas o cidadão em si... Se ele tiver a informação, ele sabe onde buscar, ele sabe que caminho tomar, ele não vai ficar vagando e achando que é injusto...". [Ricardo]

A acessibilidade arquitetônica e a circulação na cidade são relatadas com ênfase pelos entrevistados: as calçadas sujas, esburacadas e em desnível, a falta de rampas, a falta de sinalização apropriada para as pessoas com as diversas deficiências, a existência de poucos ônibus adaptados (entre outras dificuldades com o transporte público), o tempo dos semáforos, os espaços públicos etc.

"[A principal dificuldade é] Andar na rua, principalmente. Porque se eu esbarro nos outros, às vezes eu caio, e não posso; por isso, eu não posso mais sair sozinha na rua, ninguém deixa. Pegar um ônibus... Isso é terrível! (...) Mas também, se a gente anda na rua, tem umas calçadas horrorosas...". [Ângela]

Há aspectos que estão para além da acessibilidade arquitetônica: barreiras atitudinais, que potencializam as dificuldades impostas pelas barreiras arquitetônicas e, por consequência, o isolamento. Um dos exemplos trazidos é a falta de compreensão e o preconceito por parte dos motoristas de ônibus, que discriminam pessoas com deficiência (e também idosos).

"Mas já vi reclamação... Tem outro colega meu também que ele é [deficiente], que pra subir no ônibus usa muleta. Ele tem dificuldade, às vezes tem motorista que vai lá, tirar ele da cadeira, dá a mão, tem motorista que faz isso. Mas tem outros que não, se puder, quer que o cara entra rápido e tchum. Às vezes, vira a cara pro lado, isso aí já aconteceu comigo nas Clínicas. De eu dar o sinal [pro ônibus] e o cara... Eu acho que o cara me conhece, sabe que eu entro pela frente, não paga a passagem, eles não gostam muito de pegar as pessoas deficientes, as pessoas de idade...". [Sr. Jair]

É possível observar ainda que muitas das dificuldades vivenciadas e relatadas pelos entrevistados estão para além da deficiência, engendradas nas questões macrossociais, e que envolvem muitos brasileiros com ou sem deficiência. No Brasil, o acesso à educação, lazer, cultura, transporte, emprego é difícil para boa parte da população; a deficiência, as incapacidades e as desvantagens dela advindas, bem como as diferenças de oportunidades, tornam este acesso ainda mais complicado para as pessoas com deficiência. A condição ruim potencializa a dependência das pessoas com deficiência, conforme o conceito de desvantagem trabalhado por Amiralian et al. (2000): desvantagem é o prejuízo para o indivíduo, resultante de uma deficiência ou de uma incapacidade, que limita ou impede o desempenho de papéis de acordo com a idade, sexo, fatores sociais e culturais, caracterizando-se como uma discordância entre a capacidade individual de realização e as expectativas do indivíduo ou do seu grupo social, a socialização da deficiência.

O acesso aos serviços de saúde também é questão crucial. Segundo Lacerda e Valla (2007), há dificuldades na procura pelo atendimento, uma vez que a localização geográfica e a distribuição dos serviços estão em áreas mais centrais (fazendo com que pessoas que moram em áreas mais distantes tenham dificuldades); e há carências no transporte público (além do valor das tarifas), aspectos dificultados para as pessoas com deficiência devido às péssimas condições urbanas de acessibilidade. No âmbito da utilização dos serviços, a organização do atendimento, a disponibilidade dos profissionais, a capacidade dos serviços em absorver a população são outros fatores que dificultam este acesso. 
Uma especificidade relacionada ao acesso à saúde das pessoas com deficiência envolve a regularidade na dispensação de equipamentos de tecnologia assistiva e dispositivos de auxílio, além de medicamentos, sendo diversos os relatos de dificuldades neste aspecto. Ainda que regulamentado por diversas portarias e mecanismos legais, o acesso da população a estes dispositivos continua difícil.

"É caro [o aparelho auditivo]. Hoje deve tá uns sei mil... Muito caro... Não dá... Eu comprei porque eu saí do banco, eu tinha condição de comprar. (...) Eu não sei mais nenhum outro lugar que disponibiliza aparelho. É muito caro! Hoje tá uns seis mil, seis e pouco. É caro! Quem vai botar dois... Eu não tenho dinheiro, só vou comprar porque eu vou receber uma grana agora do banco, aí eu vou trocar...". [Cristina]

Ressalta-se o paradoxo enfrentado pelas pessoas com deficiência: ainda que garantido por lei, o acesso a muitos direitos conquistados pelas pessoas com deficiência permanece falho, com relatos de dificuldades e movimentos individuais/solitários em busca de conquista. Não há mecanismos que garantam - de fato e de direito - o acesso e a universalidade no Brasil, mesmo sendo um dos princípios norteadores do SUS.

Sentidos das intervenções. O viver com deficiência traz conflitos peculiares à condição, e os movimentos desse viver com deficiência são próprios a cada sujeito, e são parte dos percursos e itinerários que constroem no seu cuidado em saúde. Portanto, a utilização dos serviços de saúde também está relacionada à história de cada um dos sujeitos, e aos sentidos que construíram (e constroem) cotidianamente em seus modos de andar a vida. Estes percursos que envolvem, diretamente, a questão da deficiência, mas também itinerários daqueles que buscam os cuidados relacionados à saúde em geral, como cidadãos.

O profissional de saúde que conversa e orienta, que oferece espaço de escuta, e que valida as queixas apresentadas, é valorizado, como também é o vínculo que se estabelece com os profissionais.

"A pessoa se sente mais a vontade, mais compreendido. [...] Os médicos e as pessoas que trabalham com as pessoas que tem deficiência podem ajudar pra superar o trauma, em muitas coisas. Até os tratamentos em si. E a conversa, o diálogo, ajuda muito. Aquilo que eu te falei, quando um médico conversa com você, te atende bem... Todo tratamento que dá com as pessoas, com a pessoa conversando com você, é muito útil. E também é muito útil a assistência que dá, você se sente, se o cara atende logo... Tudo isso ajuda a superar o trauma... Ajuda muito, muito, muito mesmo". [Sr. Jair]

Demonstra-se aquilo já abordado por Lacerda e Valla (2007): a questão central da resolutividade em saúde (um dos aspectos da crise do sistema de saúde) é a relação médico-paciente. Cecilio (2006) também menciona a criação de vínculos "(a)efetivos" entre usuários e profissionais como uma das necessidades de saúde dos sujeitos, em uma relação de referência e confiança, uma relação contínua, pessoal e intransferível: um encontro de subjetividades.

Ayres (2004) chama a atenção para a importância da abertura de um interesse autêntico em ouvir o outro, em um encontro dialógico. O autor ressalta que, para esta capacidade de ausculta e diálogo, o acolhimento é um dispositivo tecnológico bastante relevante nas propostas de humanização e cuidado em saúde; e é no contínuo das interações entre usuários, profissionais e serviços - em todas as oportunidades possíveis de escuta ao outro - que se dá o acolhimento. Nas entrevistas, a validação e a valorização do espaço de escuta por elas proporcionado foram aspectos muito abordados pelas pessoas com deficiência.

É preciso considerar ainda que se estabelece um encontro intersubjetivo, em que identidades estão em contínua (re)construção a partir dele (Ayres, 2001). Porém, no caso das pessoas com deficiência, o imaginário social e cultural permeado de preconceitos e estereótipos contribui para que a atenção à saúde desta população torne-se ainda mais complexa. Estar aberto à alteridade do encontro usuárioprofissional também é fundamental nesta assistência, entendendo que já estamos imersos em um contexto em que predomina a desvalorização e o estigma da pessoa com deficiência. 
Em relação à escuta das pessoas com deficiência, um aspecto relevante é especialmente presente na história de Rubens: sua grande dificuldade na comunicação, devido a sua deficiência auditiva, parece contribuir para a não-construção de uma relação "(a)efetiva" com médicos e profissionais de saúde que o atendem. Fica clara a necessidade de adaptações para a construção desta relação vincular, a partir das deficiências e incapacidades específicas de cada sujeito.

“Eu fui [no médico], [mas a irmã tem que ir junto]. Não é ruim... Eu fui [sozinho], [porque] tava ruim o corpo, e fui no médico, [mas demorou para o médico atender]. [...] Gosto [de ir no médico]. [...] [Quando estou doente, vou] no posto de saúde e no pronto socorro também... [Sempre] Acompanhado... [Os médicos] às vezes entendem [o que falo], às vezes não... [Preciso do] aparelho... Não dá não, [pra ficar sem]. Não dá mais...". [Rubens]

Muitas vezes, a assistência a pessoas com deficiência é associada somente aos serviços de reabilitação. Porém, há demandas não relacionadas especificamente à deficiência, que devem ser contempladas nos serviços que atendem à população em geral; questões relacionadas à deficiência poderão estar presentes nestes atendimentos, e ser acolhidas e encaminhadas para os serviços de referência. No modelo hegemônico, predomina a ideia de que só devem prestar assistência a esta população os serviços especializados (Rocha, 2006; Almeida, Tissi, Oliver, 2000).

"O deficiente ficou meio rotulado que vai procurar só fisio, e não é. De uma forma geral, a gente adoece e aí vai ter que procurar vários profissionais". [Ricardo]

Ações e estratégias. Veiculação de informações, estratégias cotidianas próprias, valorização da autonomia e da independência, respeito nas relações, envolvimento em atividades de sentido e de valor para cada pessoa, e desconstrução de estereótipos foram os principais temas que emergiram.

Especificamente sobre as estratégias cotidianas próprias, faz-se necessário que os profissionais de saúde interessem-se por elas e as validem, havendo uma permeabilidade do técnico ao não-técnico (Ayres, 2004). Cada uma destas pessoas tem sua "sabedoria prática", nas palavras deste autor.

"Eu acho que [as pessoas com deficiência precisam] se ocupar, com qualquer coisa. Mesmo que as pessoas olhem, mesmo que seja um trabalho comunitário, mesmo que seja um trabalho pra ganhar dinheiro, mas sempre se ocupar. [...] E ocupar, ocupar a pessoa que tem esse problema, ocupar a mente dela... Ela pode ser um voluntário, dependendo do que ela faz, do que ela é, ela não precisa... Pode ser um voluntário, pode ajudar alguém... Melhor do que ficar no canto, vendo televisão ou aborrecida...". [Ângela]

É importante destacar que o envolvimento em atividades significativas e produtivas é fundamental para a pessoa com deficiência, em sua autoestima e dignidade, sendo que Ayres (2001) propõe ampliar o conceito de produtivo para o de sucesso prático, que pode ou não passar pela noção, tão impregnante neste aspecto, de capacidade produtiva. Assim, é preciso subsumir a ideia de êxito técnico das ações de cuidado na de sucesso existencial, podendo abrir o conceito para os diferentes modos de andar a vida, o que é particularmente importante no caso das pessoas com deficiência.

\section{Necessidades de saúde da pessoa com deficiência: proposições a partir do estudo}

A partir das narrativas e sua análise, e em consonância com o objetivo da pesquisa, foram construídos onze núcleos relacionados às necessidades de saúde da pessoa com deficiência, aos quais os serviços, programas e políticas precisam responder; destacando-se que há núcleos relacionados à saúde especificamente, mas há núcleos mais amplos, que envolvem intervenções intersetoriais.

Julga-se fundamental ressaltar, entre estas tendências gerais apresentadas, a importância, para as práticas em saúde, daquelas que envolvem a relação usuário/serviço, a fim de que os valores, desejos e necessidades possam ser, de fato, incorporados às práticas cotidianas concretas. 


\section{Acesso}

Acesso aos serviços de saúde e de reabilitação, bem como a oportunidades de emprego, estudo, lazer, convivência, circulação social. Fica premente a necessidade de propostas e ações intersetoriais diante das questões desta população.

\section{Apoio psicossocial}

Ações para elaboração das perdas e mudanças decorrentes da deficiência e sua irreversibilidade. Anteriores a uma abordagem específica, escuta, apoio e acolhimento devem ser proporcionados por todos os profissionais de saúde. Ativação de redes de suporte e ações de orientação e apoio junto à família e comunidade são outros focos de ação fundamentais.

\section{Aspectos gerais de saúde (para além da deficiência)}

Intervenção nas questões de saúde para além dos aspectos específicos da deficiência (como, por exemplo, cuidados odontológicos e ginecológicos, emergências), devendo ser identificadas e acolhidas nos serviços de saúde utilizados por todos os cidadãos.

\section{Autonomia e independência}

Devido às incapacidades decorrentes da deficiência, é necessário trazer autonomia (escolha) e a maior independência possível (fazer sozinho), trabalhando suas capacidades e potencialidades, aspectos muito valorizados pelos sujeitos entrevistados na pesquisa.

\section{Dispensação de equipamentos e dispositivos de tecnologia assistiva}

Os equipamentos de ajuda são fundamentais para alguns tipos de deficiência, possibilitando autonomia, independência e dignidade: cadeiras de rodas, bengalas, muletas, órteses e próteses são alguns exemplos. Além destes, pode haver necessidade de equipamentos menos diretamente ligados à funcionalidade e à reabilitação, como sondas e coletores, por exemplo.

\section{Informação / orientação}

Prevenção e detecção precoce das deficiências, orientação sobre o quadro da deficiência, incapacidades decorrentes, prognóstico, tratamento, procedimentos que serão realizados e reabilitação são alguns dos aspectos que envolvem este tema. Por fim, a informação e a orientação devem estar relacionadas a aspectos gerais de direitos e cidadania.

\section{Prevenção / diagnóstico precoces}

Muitas deficiências são passíveis de prevenção e poderiam ser evitadas. Além disso, precisam ser detectadas precocemente, permitindo intervenção rápida e minimizando as incapacidades decorrentes do quadro. Nas histórias desta pesquisa, este aspecto apareceu pelo lado inverso: muitos tiveram seu diagnóstico tardio e, como consequência, maiores incapacidades.

\section{Reconhecimento e garantia de direitos}

Os direitos das pessoas com deficiência estão garantidos pela constituição; porém, ainda é vigente o imaginário da caridade e do favor para com as minorias. É necessário um trabalho de 
"conscientização" e validação destes direitos. As ações não se restringem à saúde, mas devem ser intersetoriais; a comunicação, a interação e a ação conjunta entre os setores fazem-se necessárias.

\section{(Re)Encontro com atividades significativas}

(Re)encontrar atividades que Ihe façam e que Ihe tragam sentido, possibilitando a retomada de um lugar de valor, ação e interação com o contexto em que vive. Atividades estas não necessariamente ligadas ao contexto de produção, mas do sentido construído junto a cada sujeito, ligado à história individual, familiar e cultural de cada um.

\section{Validação e ajuda na construção de estratégias próprias de enfrentamento}

Validar cada sujeito como único e singular, bem como compreender e incentivar as ricas possibilidades, capacidades e saberes de cada um. A partir das dificuldades e limitações impostas pela deficiência, o sujeito vai encontrando, em seu cotidiano, estratégias próprias de elaboração e enfrentamento concreto.

\section{Vínculo com profissional de saúde}

Ser cuidado, ouvido, orientado, valorizado em uma relação de confiança mútua e dialógica com o profissional.

\section{Considerações finais}

Tomando-se, como referência para a prática em saúde, o cuidado (Ayres, 2004), em que o principal interesse é o sentido existencial da experiência do adoecimento, buscando ouvir genuinamente o outro e buscando com ele (re)construir seus projetos de felicidade, fica inerente, para a assistência à pessoa com deficiência, a (re)construção dos sentidos da vida, práticos e existenciais, numa vida que valha a pena ser vivida. Projetos de vida e desejo são ideias centrais para a resposta às necessidades de saúde das pessoas. E é preciso haver espaço nos serviços de saúde para acolher estas demandas, não somente aquelas de ordem física.

É premente que haja uma "fusão de horizontes" (Gadamer apud Ayres, 2004) entre terapeutas e pacientes, para que possam compartilhar as informações e valores de maneira mais dialógica, contribuindo para a construção de uma relação de confiança, e que também possa acolher a condição irreversível da deficiência. Faz-se necessário ajudar o sujeito a reconstruir as relações que ele estabelece entre sua deficiência, as mudanças dela advindas, seus sentimentos e sua vida. É preciso considerar seu sofrimento, entendendo que esta é uma experiência individual e singular, ainda que possa ser compartilhada com outras pessoas.

Além disso, deve-se considerar que as necessidades estão para além da saúde: direitos, cidadania, educação, transporte, lazer. Tornam-se imprescindíveis ações intersetoriais, considerando-se as especificidades que a vivência da deficiência impõe, as necessidades gerais de qualquer cidadão em seu contexto sociocultural, bem como o sentido de cada uma das proposições dentro da história de vida de cada sujeito.

Dentre todo o processo de realização do estudo, vale ressaltar que a técnica da história de vida adotada concretizou a possibilidade de abrir o espaço para o pensar do sujeito sobre sua própria história e sobre suas necessidades. A pesquisa apresentou um recorte em sua população, em um grau que possibilitasse a participação e a realização das entrevistas. Ainda que tomemos a deficiência como um tema transversal nas práticas em saúde, sugerem-se outros trabalhos que aprofundem cada uma das deficiências, avaliando as possíveis especificidades de cada grupo, bem como aqueles que considerem os diferentes graus de acometimento. 


\section{Colaboradores}

Marilia Bense Othero participou de todas as etapas de elaboração do artigo: revisão bibliográfica, elaboração, discussões e revisão do texto. José Ricardo de Carvalho Mesquita Ayres participou das discussões e da revisão do texto, uma vez que foi orientador da primeira autora na elaboração da pesquisa e do artigo.

\section{Referências}

ALMEIDA, M.C.; TISSI, M.C.; OLIVER, F.C. Deficiência e atenção primária em saúde: do conhecimento à invenção. Rev. Ter. Ocup. Univ. São Paulo, v.11, n.1, p.33-42, 2000.

AMIRALIAN, M.L.T. et al. Conceituando deficiência. Rev. Saude Publica, v.34, n.1, p. 97-103, 2000.

AYRES, J.R.C.M. Organização das ações de atenção à saúde: modelos e práticas. Saude Soc., v.18, supl. 2, p.11-23, 2009.

O cuidado, os modos de ser (do) humano e as práticas de saúde. Saude Soc.,

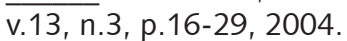

Sujeito, intersubjetividade e práticas de saúde. Cienc. Saude Colet., v.6, n.1, $\overline{\text { p.63-72, } 2001 .}$

BERNARDES, L.C.G. et al. Pessoas com deficiência e políticas de saúde no Brasil: reflexões bioéticas. Cienc. Saude Colet., v.14, n.1, p.31-8, 2009

BRASIL. Ministério da Saúde. Secretaria de Atenção a Saúde. Política Nacional de Saúde da Pessoa Portadora de Deficiência. Brasília: Editora do Ministério da Saúde, 2008. 72p. (Serie E. Legislação em Saúde).

CAMPOS, C.M.S.; MISHIMA, S.M. Necessidades de saúde pela voz da sociedade civil e do Estado. Cad. Saude Publica, v.21, n.4, p.1260-8, 2005.

CANGUILHEM, G. O normal e patológico. Rio de Janeiro: Forense Universitária, 1982.

CECILIO, L.C.O. As necessidades de saúde como conceito estruturante na luta pela integralidade e equidade na atenção em saúde. In: PINHEIRO, R.; MATTOS, R.A. (Orgs.). Os sentidos da integralidade na atenção e no cuidado à saúde. 6.ed. Rio de Janeiro: UERJ, IMS/Abrasco, 2006. p.115-28.

DINIZ, D. O que é deficiência. São Paulo: Brasiliense, 2007. (Coleção Primeiros Passos).

FARIAS, N.; BUCHALLA, C.M. A classificação internacional de funcionalidade, incapacidade e saúde da Organização Mundial de Saúde: conceitos, usos e perspectivas. Rev. Bras. Epidemiol., v.8, n.2, p.197-3, 2005.

GOFFMAN, E. Estigma: notas sobre a manipulação da identidade deteriorada. Trad. Márcia Bandeira de Mello Leite Nunes. 4.ed. Rio de Janeiro: LTC, 1988.

GONÇALVES, R.C.; LISBOA, T.K. Sobre o método da história oral em sua modalidade trajetórias de vida. Rev. Katál., v.10, n.esp., p.83-92, 2007.

GUIRARDI, M.I.G. Representações da deficiência e práticas de reabilitação: uma análise do discurso técnico. 1999. 150p. Tese (Doutorado em Psicologia) - Universidade de São Paulo, São Paulo. 1999.

HOULTZ, A. Versiones biográficas/versiones autobiograficas: las entrevistas y el material autobiografico como medio de comunicación y método para recabar información. Hist. Antropol. Fuentes Orales, v.2, n.18, p.63-72, 1997.

IBGE. Censo Demográfico 2000: características gerais da população. Rio de Janeiro: IBGE, 2003. 
LACERDA, A.; VALLA, V.V. As práticas terapêuticas de cuidado integral à saúde como proposta para aliviar o sofrimento. In: PINHEIRO, R.; MATTOS, R.A. (Orgs.). Cuidado: as fronteiras da integralidade. 3.ed. Rio de Janeiro: Cepesc/UERJ, Abrasco, 2006. p.91-102.

MATTOS, R.A. A integralidade na prática (ou sobre a prática da integralidade). Cad. Saude Publica, v.20, n.5, p.1411-6, 2004.

MENDES-GONÇALVES, R.B. Práticas de saúde: processos de trabalho e necessidades. São Paulo: CEFOR, 1992.

MERHY, E.E. Modelo de atenção à saúde como contrato social. Texto Apresentado na $11^{\text {a }}$ Conferência Nacional de Saúde. Brasília, 2000 (mimeogr.)

ONU. Convenção Internacional dos Direitos da Pessoa com Deficiência, 2006.

Disponível em: <www.mp.pe.gov.br>. Acesso em: 05 jan. 2011.

OTHERO, M.B. Atenção à saúde da pessoa com deficiência: necessidades sob a perspectiva dos sujeitos. 2010. 315p. Dissertação (Mestrado em Ciências) - Faculdade de Medicina da Universidade de São Paulo, São Paulo, 2010.

PEREIRA, R. Anatomia da diferença: normalidade, deficiência e outras invenções. São Paulo: Casa do Psicólogo, 2008.

ROCHA, E.F. Reabilitação de pessoas com deficiência: a intervenção em discussão. São Paulo: Roca, 2006.

ROCHA, E.F.; BRUNELLO, M.I.B. Avaliação qualitativa em Terapia Ocupacional: princípios, métodos e técnicas de coleta de dados. In: CAVALCANTI, A.; GALVÃO, C. (Orgs.).

Terapia Ocupacional: fundamentação e prática. Rio de Janeiro: Guanabara Koogan, 2007. p.44-8.

SCHRAIBER, L.B. Pesquisa qualitativa em saúde: reflexões metodológicas do relato oral e produção de narrativas em estudo sobre a profissão médica. Rev. Saude Publica, v.29, n.1, p.63-74, 1995.

SCHRAIBER, L.B.; MENDES-GONÇALVES, R.B. Necessidades de saúde e atenção primária. In: SCHRAIBER, L.B.; NEMES, M.I.B.; MENDES-GONÇALVES, R.B. (Orgs.). Saúde do adulto: programas e ações na unidade básica. 2.ed. São Paulo: Hucitec, 2000. p.29-47. 
OTHERO, M.B.; AYRES, J.R.C.M. Necesidades de salud de la persona con discapacidad: la perspectiva de los sujetos a través de historias de vida. Interface - Comunic., Saude, Educ., v.16, n.40, p.219-33, jan./mar. 2012.

Esta investigación tuvo como objetivo identificar las necesidades de salud de las personas con discapacidad, desde la perspectiva de los sujetos. Se realizó un estudio cualitativo, através de la técnica de la historia devida que incluyó a personas con discapacidades físicas, auditivas y visuales, congênitas y adquiridas, que recibieron tratamiento en el Sistema Único de Salud. Se discutió: la experiência de la discapacidad; independencia, autonomía y apoyo; acceso y derechos; sentido de las intervenciones; acciones y estratégias. Once necesidades de salud fueron listadas: acceso; apoyo psicosocial; cuestiones generales de salud; autonomía e independencia; dispensación de equipos y dispositivos de tecnología asistida; información / orientación; prevención y diagnóstico precoces; reconocimiento y garantia de derechos; recuperación de actividades significativas; validación y ayuda en la construcción de sus propias estratégias de afrontamiento; vínculo con los profissionales de la salud. Las necesidades identificadas incluyen aspectos específicos de la atención en salud, pero también incluyen otras dimensiones, indicando la importancia de acciones integradas y entre sectores.

Palabras clave: Personas con discapacidad. Necesidades de salud. Historia de vida. Investigación cualitativa. 
